\title{
Does College Level the Playing Field?
}

Ray Boshara

$\mathbf{W}$ hether the topic is responding to poverty and inequality or expanding access to opportunity and the American Dream, college is always among the central recommendations. Yet, in August of 2015, the Center for Household Financial Stability at the Federal Reserve Bank of St. Louis published research by Center economist William R. Emmons and Center analyst Bryan J. Noeth that found that a college degree predicted rising levels of family wealth between 1992-2013 for college-educated Whites and Asians, but declining levels of wealth over that period for college-educated Blacks and Hispanics. While college does, generally, lead to more wealth within all races and ethnicities, it was clearly a different story when considering the change in wealth over those two decades. Surprised, and in response to national media attention, Center staff organized a May 2016 research symposium that, through commissioned papers and discussion, aimed to begin to understand the underlying explanations of this troubling finding. The result of that inquiry is this dedicated issue of the Review.

Following this brief summary and refection, the issue begins with a framing paper by Center staff and is followed by new research papers exploring racial differences in homeownership and mortgages, family structure, inheritances and other family transfers, student loans, and college environments. Along with reflections and comments offered by other symposium panelists, we hope this volume helps "peel back the onion" on the perplexing and disturbing question of why post-secondary education has, since 1992, been associated with radically different returns among college graduates of different races.

In their provocative paper, which provides the overall framing for the symposium, William R. Emmons and Lowell R. Ricketts challenge standard economic models that attempt to explain differences in wealth outcomes with differences in financial choices or behavior alone. While their research suggests that observable factors can explain over two-thirds of the Black-White wealth gap, they note that this model assumes that all racial and ethnic groups (i) generate equal returns to education and (ii) face the exact same choices and opportunity structures. Given concerns about these assumptions, Emmons and Ricketts posit an alternative framework that assigns differences in education, family structure, financial decisions,

Ray Boshara is senior adviser and director of the Center for Household Financial Stability, Federal Reserve Bank of St. Louis.

Federal Reserve Bank of St. Louis Review, First Quarter 2017, 99(1), pp. 1-5. http://dx.doi.org/10.20955/r.2017.1-5

( ) 2017, Federal Reserve Bank of St. Louis. The views expressed in this article are those of the author(s) and do not necessarily reflect the views of the Federal Reserve System, the Board of Governors, or the regional Federal Reserve Banks. Articles may be reprinted, reproduced, published, distributed, displayed, and transmitted in their entirety if copyright notice, author name(s), and full citation are included. Abstracts, synopses, and other derivative works may be made only with prior written permission of the Federal Reserve Bank of St. Louis. 
and luck not to individual choice alone but also to systemic and structural factors. While differences in observable financial behaviors and choices-such as high concentrations of wealth in housing and high debt burdens - appear to be the proximal causes of diverging wealth outcomes, the underlying reasons for these choices are unobservable. Emmons and Ricketts conclude, "[A] structural-determinants framework suggests the vast majority of Black-White and Hispanic-White wealth gaps may lie beyond the scope of individual actions or marginal policy changes directed at educational attainment, family structure, financial decisionmaking, or even wealth redistribution. Instead, the gaps appear to be deeply rooted in unobservable factors [that underlie observable financial choices] that may include discrimination or other long-lasting disadvantages."

The significance of this novel framing, especially among mainstream economists, was noted by the paper's three discussants: Angelyque Campbell, a Federal Reserve analyst; Su Jin Jez, an academic; and Eric Rodriguez, an advocate. Each discussant offers a different perspective: Jez, for example, notes that "This article's framing and more theoretical underpinnings that considered structural factors that impact asset accumulation was innovative, laudable, and exciting." Campbell gives Emmons and Ricketts "tremendous credit for structuring a research framework that attempts to answer the yet unsolvable puzzle of the definitive cause of the racial wealth gap." Each recognizes the limits of both the behavioral mode and the assumption that education generates equal returns among races, while remarking that it is wealth itself that predicts education - that wealth begets wealth; that wealth protects the value of an education in a downturn or transition; and that the earlier in life one has wealth and other advantages, the more likely one is to have an education that leads to and protects more wealth. In other words, for them it may not be surprising that education or education alonewhile critical for economic success-does not fully explain or meaningfully close racial and ethnic wealth gaps and that a systemic or structural framing may offer a better explanation of persistent gaps. The discussants further comment on the importance of working across disciplines (Campbell), the unique challenges and contributions of Latinos (Rodriguez), and the role of homeownership and quality differences among colleges in explaining racial and ethnic wealth gaps (Jez).

In their conference paper focusing on differing experiences with post-secondary education, Darrick Hamilton and William Darity Jr. also underscore the centrality of wealth in explaining racial differences in educational outcomes and emphasize the importance of not framing the challenge in terms of personal behavior. They write, "By defining the central problem facing the Black community as not the deep-seated structures that perpetuate racism, but rather deficiencies internal to Blacks themselves, the focus of policy would become the rehabilitation of the Black family as opposed to addressing on-going structural barriers such as inadequate capital finance endowment." In their view, several factors help explain why college-educated Blacks accrue less wealth than college-educated Whites: Blacks are more likely to accumulate student debt, to accumulate more student debt, and to attend for-profit colleges. They also note that the wealth gap actually increases when comparing Blacks and Whites with graduate or professional degrees. Yet the perception that wealth derives from education remains, something Hamilton and Darity caution in their recent brief, "Umbrellas 
Don't Make It Rain": Observing greater levels of education among wealthier families does not necessarily mean that educational attainment leads to wealth, and there is a similar tendency to overestimate the economic returns to education. In fact, as they note, having wealth "predisposes" families to more access to higher levels of education. Hamilton and Darity conclude that, "Despite the promise of integration, the college experience remains markedly different based on race." And, since education alone will not close gaping racial wealth gaps, they advocate for a bold program of "baby bonds" - automatic wealth endowments at birth for every newborn child, regardless of race, but with greater endowments for all low-wealth families, regardless of race, which will disproportionately benefit minority families.

Cory Koedel, also looking at differing college experiences, notes significant racial disparities in college completion rates, STEM degrees, and post-college earnings, all of course impacting subsequent opportunities for wealth accumulation. Koedel, however, by focusing on gaps in graduation and STEM degree attainment rates between Black and White students at Missouri's four-year public universities, finds that disparities can be explained entirely by students' academic preparation and environments prior to enrollment in college. By focusing on the importance of pre-college academic training, Koedel reflects findings by James J. Heckman and others who argue that early investments in human capital development are best poised to combat race-based gaps in educational attainment.

Robert I. Lerman brings a new perspective to the symposium's central question: How could differences in family structure (namely, whether family members are married or single) potentially explain differences in wealth outcomes between Black and White college graduates? He notes that, even among college graduates, over two-thirds of White-family heads between ages 25 and 59 were married, while only about 40 percent of Black-family heads were married. He then cites several studies showing that marriage is associated with "increased male earnings, higher family incomes, enhanced wealth building, and a longer-term perspective that is conducive to asset building." These differences are even starker among households with children. Yet, even with these differences, Lerman finds that "family status changes between 2007 and 2013 were too small to account for much of the wealth decline among Black and Hispanic college graduates" and that even married-couple Black and Hispanic families suffered sharp declines in home equity and net worth. But Lerman cautions that these findings do not mean that a college degree and marriage are not critical to building wealth: While the wealth gap between married Black college graduates and unmarried graduates has declined since 2007, married Black couples retained at least a 70 percent wealth advantage over unmarried couples.

In a wide-ranging keynote conversation with William A. "Sandy" Darity, moderated by me, Darity also noted his appreciation of Emmons and Ricketts's structural framing over postracial, behavioral framing, but suggested that more attention might be paid to parental wealth (whether during life or at death) in understanding racial wealth gaps. He further noted studies showing similar savings rates, portfolio performance, and money-management capabilities among Blacks and Whites, casting further doubt on behavioral models. Darity also pushed back against Robert Putnam's key observation in his 2015 book, Our Kids, that America faces, primarily, a class instead of race challenge; for Darity, while Putnam is correct that being raised by a single, non-college-educated parent poses great risks to a child's future financial 
security, race "drastically alters the odds of both your social and class location, as well as the wealth position that you may have access to in this society." He then references Dalton Conley's important research showing that Black children born to college-educated, married parents have a much greater chance of downward mobility than similar White children. The effect of race, he notes, is well illustrated in a study by Janelle Jones and John Schmitt, who compared Black and White Harvard MBAs and found a \$5,000 pay differential at the beginning of their careers that then balloons to $\$ 100,000$ per year within six to eight years of graduation. He also discussed similar studies-focusing on job seekers, stereotypes, and college campus experiences-where clear racial biases persist. He closed by reiterating his and Hamilton's "baby bonds" proposal and held it up as an example of a "race conscious" policy-meaning that, while not targeted towards Blacks or other non-Whites (which would be "race specific"), the policy would disproportionately benefit minorities. So, for example, Mark Zuckerberg's child might receive a $\$ 50$ baby bond at birth, while a family from the lowest end of the wealth distribution-whether White, Black, Hispanic, or Asian—-might receive $\$ 50,000$. Since a greater proportion of minorities have wealth in the bottom of the wealth distribution, they would disproportionately benefit.

Tatjana Meschede, Joanna Taylor, Alexis Mann, and Thomas Shapiro explore another less researched but increasingly important explanation: the role of financial transfers from parents and others. Meschede et al., using a different data set (the Panel Study of Income Dynamics), were first able to corroborate Emmons and Noeth's finding that college-educated Blacks and Whites have had diverging wealth outcomes since the early 1990s. But then they looked at the specific role that financial transfers-inheritances, of course, but importantly also transfers for education, rent support, home purchases, wedding gifts, enrichment activities, etc.-play in explaining those outcomes. They find that estimating just the impact of inheritance or large financial gifts over the study period decreases the racial wealth gap by close to $\$ 40,000$, or 20 percent. It is important to bear in mind here that direct transfers may underestimate the effect on wealth. For example, a $\$ 20,000$ transfer to help with a home purchase or education is likely itself to lead to more wealth given the generally appreciating value of an education or a home, just as a college degree financed without student loans will lead to more wealth, as will a transfer to prevent a foreclosure. Moreover, Meschede et al. find that collegeeducated Blacks are not only less likely to receive transfers and to receive smaller transfers, they are also more likely to give financial support to their parents or other family members. This then leads to the authors' closing, normative, and important question: "What is 'better'money in stocks and bonds and savings accounts, or helping to send nieces to college and supporting older parents with living and health situations? Wealth is a means, not a goal."

This volume's final paper turns to the role of homeownership-foreclosures and delinquencies, specifically_in explaining diverging wealth outcomes, Carlos Garriga, Don Schlagenhauf, and Lowell R. Ricketts look at home purchases between 2004 and 2008. They find that Black and Hispanic households experienced significantly higher serious delinquency and foreclosure rates than White and Asian households. They observe that minority borrowers faced repayment difficulties well before the crash and that those difficulties were intensified by the economic downturn. Surprisingly, Hispanic borrowers that earned the most (those with incomes 
greater than the median) had the greatest prevalence of foreclosures, a finding which may help to explain why college-educated Hispanics lost more wealth during the Great Recession than their non-college educated peers. Using logit regression analysis they find that over half of the Nonwhite-White gap in foreclosure frequency is explained by underwriting standards, loan structure, and regional effects. Regional factors were most pertinent for Hispanic borrowers given that over 50 percent of foreclosures were concentrated in California and Florida, two of the hardest hit housing markets.

While it is clear that the answer to the symposium's title question "Does college level the playing field?" is "No," or at least not college alone, the symposium did appear to "peel back the onion" by beginning to explain why the wealth outcomes of college-educated Blacks and Whites have diverged since 1992. Several research findings and ideas contributed to this understanding. First, reframing the inquiry-away from a "postracial" behavioral view that assumes equal returns on education and equal financial choices and toward one that assumes neither and instead assigns greater weight to unobservable but systemic issues that include historical and ongoing discrimination-itself opens up the possibility of new questions and alternative explanations. Second, both racial differences in pre-college academic preparation and reliance on student loans once in college help explain radically different wealth outcomes between Blacks and Whites. Further research was presented showing the significant effect of race on earnings and job prospects even among otherwise identical applicants and graduates and that graduate or professional degrees actually exacerbate wealth gaps between Whites and Blacks.

College, that is, cannot level the playing field when equal degrees generate unequal returns. In fact, some believe we are more likely to level the playing field through wealth itself than through college, or at least than through college alone. To invoke Hamilton and Darity, more umbrellas (education) might not be the cause of more rain (wealth), but we are quite likely to have more umbrellas if we have more rain.

Other symposium research highlighted the disparate impacts of homeownership-of foreclosures and delinquencies, especially-on wealth, as well as the less-recognized but increasingly important fact that Blacks receive fewer and smaller wealth transfers from family members and, controlling for income, are more likely than Whites to transfer wealth out of their households to help parents and other extended family members survive and thrive. Finally, while differences in family structures between Blacks and Whites were not clearly associated with diverging wealth outcomes since 1992, marriage (that is, having two earners and asset accumulators) could help us understand wealth gaps between Blacks and Whites, college educated or not.

So while we believe the symposium contributed to our understanding of diverging wealth outcomes between college-educated Whites and Blacks since 1992, we hope the papers in this volume spark even more research and discussion-and an awareness by policymakers, advocates, philanthropists, and others that college, while essential, is only one critical response among many to truly broaden wealth, opportunity, and economic security in the United States in the years ahead. 
